\title{
REMOVAL OF PENTACHLOROPHENOL FROM AQUEOUS SOLUTIONS BY ADSORPTION ON DATE-PITS AVTIVATED CARBON
}

El-Samanoudy, M. A. ${ }^{(1)}$; Abo El-Enien, S. A. ${ }^{(2)}$; El-Gendy, A. S..$^{(3)}$ and Al-Refaie, Ibtsam, $\mathrm{K}^{(4)}$

1) Faculty of Engineering, Ain Shams University 2) Faculty of Science, Ain Shams University 3) Institute of Environmental Studies and Research, Ain Shams University 4) Public Authority of Environment, Kuwait

\begin{abstract}
Adsorbable organic halide (AOX) compounds known with their toxic effect, produced as by-product for drinking water disinfection. The present work studied the removal of pentachlorophenol (PCP) as a model AOX compound in water. The use of a locally prepared date-pit activated carbon (DPAC) as adsorbent of pentachlorophenol from aqueous solutions was examined over $\mathrm{pH}$ range (2-11) and at different temperatures 25, 35, 45 and $55^{\circ} \mathrm{C}$. Langmuir, Frendulich, Temkin and Redlich-Peterson isotherm models were tested for modeling the adsorption isotherm at equilibrium. date-pit activated carbon examined by Elemental Analysis and FTIR.
\end{abstract}

Keywords: Drinking water treatment; Pentachlorophenol; Date-pits activated carbon.

\section{INTRODUCTION}

Chlorine has been used for drinking water disinfection since the beginning of the last century and it still remains as the major chemical for this purpose around the world. It is introduced in water as a gas or as the sodium 
or calcium hypochlorite (Praus, 2003). Chlorination generates a wide variety of chlorinated organic compounds, collectively called disinfection by products DBPs, mainly halogenated compounds that originate by the reaction of free chlorine and/or bromine with precursors or natural organic matters (NOM). Adsorbable organic halides (AOX), represents the organically bound halogens - chlorine, bromine and iodine (but not fluorine) contained in a sample which can be adsorbed on activated carbon. Chlorophenolic compounds including pentachlorophenol (PCP) constitute a major component of AOX (Ghosh et al., 2011). These compounds causes liver and kidney damage, reduce gonad development and known to induce hormonal disorders in many aquatic species. (Sumathi and Hung 2004; Savant et al., 2006). The by-product control strategy in water treatment plants includes removing the DBP precursors, changing disinfectants, and/or removing DBPs themselves (Praus, 2003) and for the removal of AOXs, adsorption is regarded as a promising method. The preparing of activated carbon utilizing natural wastes adsorbents has an environmental and commercials advantage over other removal methods. Date-pits are common agricultural waste available in large quantity in the palm-growing countries such as the Kuwait. Banat et al. (2002) used raw date-pits and date-pit activated carbons for the adsorption of zinc and copper ions from water. Activated date-pit carbons were also used for the adsorption of cadmium ions (Banat et al., 2003). Date -pit activated carbon also used as adsorbent of Aluminium (Al-Muhtaseb et al. 2008), Cobalt (Al-Jlil, 2012) Phenolic compounds and Methylene Blue (Abdulkarim et al., 2002), organic compounds from water (Merzougui and Addoun, 2008), 
heavy metal (Esmael et al., 2014) while Abdel-Ghani et al., (2015) used activated carbons prepared from corn wastes to remove PCP adsorption from aqueous solution.

The focus of the present work is to evaluate the adsorption potential of date-pits based activated carbon in removing of Pentachlorophenol as a model of AOXs from aqueous solutions at different temperatures and $\mathrm{pH}$ values. However, to the best of the authors' knowledge, there is no published literature for the adsorption of PCP on date-pit activated carbon.

\section{EXPERIMENTAL}

\section{Materials and Methods:}

\subsection{Pentachlorophenol solutions:}

Stock solutions were prepared by dissolving pentachlorophenol (SigmaAldrich Chemical Company 99.0\%) in deionized water followed by serial dilutions.

\subsection{Preparation of activated carbon}

The preparation of activated carbon from the palm-date pits involves three steps: boiling, soaking and a combined step of carbonization and activation of pits (Al-Attas, 2003 and Esmael et al., 2014). In the first step, the pits were boiled for about three hours then; the boiled pits were dried in an drying oven at $110^{\circ} \mathrm{C}$ for 24 hours and crushed. The second step is soaking. The solution commonly used in the chemical treatment process of producing activated carbon is phosphoric Acid $\left(85 \% \mathrm{H}_{3} \mathrm{PO}_{4}\right)$ at $25{ }^{\circ} \mathrm{C}$ and for 12 hours, then dried in an oven at $120^{\circ} \mathrm{C}$ for one hour. The final step is the process of carbonization and activation. The date pits were placed on a 
metallic plate and subjected to an average temperature of $400^{\circ} \mathrm{C}$ for 2 hours under constant flow of nitrogen. The product was put in a flask and distilled hot water was added. Then, the pits were washed with distilled boiling water until the $\mathrm{pH}$ was achieved (6.7), and then the product was dried in an drying oven at $120^{\circ} \mathrm{C}$ overnight in order to remove any undesired moisture within the particles.

\section{Characterization of Activated Carbon:}

\subsection{Surface Analysis:}

The specific surface area and total pore volume were measured using a multipurpose apparatus Nova 2000 analyzer, Quantachrome Instruments (Japan) the method employed was adsorption of high-purity nitrogen by the Brunauer-Emmett-Teller (BET) method.

\subsection{FTIR:}

Fourier Transform Infrared Spectroscopy (FTIR) analysis of about $1 \mathrm{mg}$ of DPAC were carried. The samples were grinded and milled with $100 \mathrm{mg}$ $\mathrm{KBr}$ to form a fine powder. This powder was then compressed into a thin pellet under7 tons for 5 minutes. The sample was then analyzed using Shimadzu 6100A spectrometer and the spectrum was recorded in a spectral range of $400-4000 \mathrm{~cm}^{-1}$.

\section{AOXs Analysis:}

AOX analyzer multi X2000-Germany was used for the determination of AOX in the collected samples according to Method No. ISO 9562:2004. 


\section{Effect of solution pH:}

The effect of $\mathrm{pH}$ on adsorption capacity of PCP onto DPAC, was evaluated. Batch experiments were performed at $\mathrm{pH}$ 2,4.7, 9 and 11 using an adsorbent dose of 0.1 g. $\mathrm{dm}^{-3}$ and PCP solutions volume $0.05 \mathrm{dm}^{3}$ at room temperature for $240 \mathrm{~min}$, where the initial concentration of PCP is $300 \mu \mathrm{g}$. $\mathrm{dm}^{-3}$. The $\mathrm{pH}$ of the initial solution was adjusted by using $0.1 \mathrm{M} \mathrm{HCl}$ and 0.1 $\mathrm{M} \mathrm{NaOH}$

\section{Effect of Contact Time:}

Effect of contact time on the adsorption capacity evaluated by contacting a constant mass $(0.1 \mathrm{~g})$ of date-pit activated carbon with a fixed volume $(50 \mathrm{ml})$ of two concentrations (500 and $1000 \mu \mathrm{g} . \mathrm{dm}^{-3}$ ) for different intervals of contact time until equilibrium was reached

\section{Adsorption Isotherm:}

Batch adsorption experiments were carried out using bottle-point method (El-Geundi, 1991). In this method stock solution of PCP $\left(5000 \mu \mathrm{g} . \mathrm{dm}^{-3}\right)$ was subsequently diluted to the required initial concentrations over wide range (50- $2750 \mu \mathrm{g} \cdot \mathrm{dm}^{-3}$ ). Adsorption capacity of the activated carbon towards PCP was determined by contacting a constant mass $(0.1 \mathrm{~g})$ of date-pit activated carbon with a fixed volume $(50 \mathrm{ml})$ of different initial concentrations of PCP solution in sealed glass bottles. The experiments were done at different temperatures: $25,35,45$ and $55^{\circ} \mathrm{C}$. After shaking in isothermal water-bath shaker for $4 \mathrm{~h}$ (240 min) until equilibrium was reached, contents were centrifuged. Supernatant samples saved in amber glass wide-mouth screw cap bottles and zero headspace, stored cool at 0 to $4{ }^{\circ} \mathrm{C}$ and maintained in this 
condition away from light until analysis. The amount of PCP adsorbed onto DPAC, $\mathrm{q}_{\mathrm{e}}\left(\mu \mathrm{g} \cdot \mathrm{g}^{-1}\right)$, was calculated by the following equation:

$$
\mathrm{qe}=\frac{(\mathrm{Co}-\mathrm{Ce}) \mathrm{V}}{m}
$$

Where $\mathrm{C}_{\mathrm{o}}$ and $\mathrm{C}_{\mathrm{e}}$ are the initial and equilibrium concentrations of PCP solution (ppb), respectively. $\mathrm{V}$ is the total volume of the solution (1), and $\mathrm{m}$ is the mass of DPAC used (g).

The adsorption equilibrium data were fitted into four different isotherm models to determine the most suitable model to represent the adsorption process. The isotherms used are the Langmuir, the Freundlich, the Temkin, and the Redlich-Peterson isotherm.

\subsection{Langmuir isotherm:}

The Langmuir isotherm is valid for monolayer adsorption on a homogenous adsorbent surface containing a finite number of identical site and no interaction between adsorbent molecules. The Langmuir expression may be converted into a linear form:

$$
\frac{C_{e}}{q_{e}}=\frac{a_{L}}{K_{L}} C_{e}+\frac{1}{K_{L}}
$$

where $\mathrm{Ce}$ is the equilibrium concentration $\left(\mu \mathrm{g} / \mathrm{dm}^{-3}\right)$; qe is the adsorption capacity at equilibrium $(\mu \mathrm{g} / \mathrm{g})$; and $\mathrm{K}_{\mathrm{L}}$ is the sorption equilibrium constant $\left(\mathrm{dm}^{-3} / \mathrm{g}\right)$.The essential characteristics of the Langmuir isotherm can be expressed in terms of a dimensionless equilibrium parameter $\left(R_{L}\right)$, which is defined by:

$$
R_{L}=\frac{1}{1+a_{L} \cdot C_{0}}
$$


Where $\mathrm{R}_{\mathrm{L}}$ is a dimensionless constant separation factor, Since $\left(\mathrm{C}_{\mathrm{ref}}\right)$ is the highest liquid-phase concentration $\left(\mu \mathrm{g} \cdot \mathrm{dm}^{-3}\right)$ encountered (i.e. $\mathrm{C}_{\mathbf{r e f}}=\mathrm{C}_{\mathbf{0}}$ ). and $\mathrm{a}_{\mathrm{L}}$ is the Langmuir adsorption constant $\left(\mathrm{dm}^{3} \cdot \mathrm{g}^{-1}\right)$.

\subsection{Freundlich Isotherm:}

Freundlich isotherm in the other hand assumes heterogeneous surface energies, in which the energy term in Langmuir equation varies as a function of the surface coverage (Weber and Chakravort, 1974). The experimental equilibrium data has been analyzed using the Freundlich isotherm as given by linnera equation (9).

$$
\log \mathrm{q}_{\mathrm{e}}=\log \mathrm{K}_{\mathrm{F}}+(1 / \mathrm{n}) \log \mathrm{C}_{\mathrm{e}}
$$

Where $\left(K_{F}\right.$ and $\left.n\right)$ are the Freundlich constants. The $K_{F}$ value is related to the adsorption capacity; while $\mathrm{n}$ value is related to the adsorption intensity. The magnitude of exponent (n) gives an indication of the favorability and capacity of the adsorbent/adsorbate system. Values of (n) greater than 1 represent favorable adsorption according to (Treybal, 1985).

\subsection{Temkin Isotherm:}

Temkin model considered the effects of indirect adsorbate/adsorbate interactions on adsorption isotherms. The heat of adsorption of all molecules in the layer would decrease linearly with coverage due to adsorbate/adsorbate interactions. The Temkin isotherm has been used in the form as follows (Temkin, 1941):

$$
q_{e}=B_{T} \ln A_{T}+B_{T} \ln \left(C_{e}\right)
$$

Where $\mathrm{B}=\mathrm{RT} / \mathrm{b}, \mathrm{T}$ is the absolute temperature $(\mathrm{K}), \mathrm{R}$ is the universal gas constant $(8.314 \mathrm{~J} / \mathrm{gmol} . \mathrm{K}), \mathrm{A}_{\mathrm{T}}$ is the equilibrium binding constant corresponding to the maximum binding energy $\left(\mathrm{dm}^{3} \cdot \mu \mathrm{g}^{-1}\right), \mathrm{b}_{\mathrm{T}}$ is Temkin 
isotherm constant $\left(\mathrm{J} \cdot \mathrm{g}-\mathrm{mol}^{-1}\right)$ and the constant $\mathrm{B}_{\mathrm{T}}$ is related to the heat of adsorption (dimensionless).

\subsection{Redlich-Peterson Isotherm:}

The Redlich-Peterson isotherm contains three parameters and involves the features of both the Langmuir and the Freundlich isotherms. The linear form is shown in equation (6) from which the constants $\left(\mathrm{K}_{\mathrm{RP}}, \mathrm{a}_{\mathrm{RP}}\right.$ and $\left.\beta\right)$ which characterize the isotherm, can be determined as:

$$
\log \left(\frac{K_{R P} C_{e}}{q_{e}}-1\right)=\log a_{R P}+\beta \log C_{e}
$$

Where $\beta \leq 1, \mathrm{~K}_{\mathrm{RP}}$ is the modified Langmuir constant $\left(\mathrm{dm}^{3} \cdot \mathrm{g}^{-1}\right), \mathrm{a}_{\mathrm{RP}}\left(\mathrm{dm}^{3} \cdot \mu \mathrm{g}^{-1}\right)$ and $\beta$ are constants. Plotting $\left(\log \left[\left(\mathrm{K}_{\mathrm{RP}} \mathrm{C}_{\mathrm{e}} / \mathrm{q}_{\mathrm{e}}\right)^{-1}\right]\right)$ against $\left(\log \mathrm{C}_{\mathrm{e}}\right)$ yields a straight line of slope; $\beta$ and intercept $=\log \mathrm{a}_{\mathrm{RP}}$. The isotherm parameters are listed with the corresponding values of $\mathrm{R}^{2}$ and ARE in Table (3).

\section{Simulation Results and Correlations:}

Using the estimated parameters of the different models; Langmuir, Freundlich, Temkin and Redlich-Peterson, the theoretical isotherm curves were predicted using known values of $\mathrm{C}_{\mathrm{e}}$. In order to quantitatively compare the applicability of different models, the average relative error (ARE) was calculated using equation (7) (Kapoor, and Yang, 1989):

$$
A R E=\frac{100}{N}\left[\sum_{i=1}^{N}\left|\frac{q_{e, c a l}-q_{e, \exp }}{q_{e, \exp }}\right|\right]
$$

Where $\mathrm{N}$ is the number of data points, $\mathrm{q}_{\mathrm{e}, \exp }$ and $\mathrm{q}_{\mathrm{e}, \mathrm{cal}}\left(\mu \mathrm{g} \cdot \mathrm{g}^{-1}\right)$ are the experimental and the calculated values of the equilibrium adsorbate solid concentration in the solid phase, respectively. The values of ARE a measure 
of the fitting of the data to an isotherm equation, small values of ARE would indicate a perfect fit.

\section{RESULTS AND DISSCUSSIONS}

\section{Characterization of prepared activated carbon:}

\subsection{Surface Analysis:}

The BET surface area of the prepared activated carbon was found to be 825 $\mathrm{m}_{2} / \mathrm{g}$. The density and surface properties of date-pits activated carbon (DPAC) are shown in Table (1).

Table (1): Physical properties of date-pits activated carbon.

\begin{tabular}{||l||l|}
\hline Solid-phase density $\left(\rho_{\mathrm{s}}\right)\left(\mathrm{g} / \mathrm{cm}^{3}\right)$ & $(1.04) \pm 0.04$ \\
\hline Particle density $\left(\rho_{\mathrm{p}}\right)\left(\mathrm{g} / \mathrm{cm}^{3}\right)$ & $(0.50) \pm 0.04$ \\
\hline Porosity $\left(\varepsilon_{\mathrm{p}}\right)$ & $0.52 \pm 0.01$ \\
\hline Specific Surface area $\mathrm{S}_{\mathrm{BET}}\left(\mathrm{m}^{2} / \mathrm{g}\right)$ & $825 \pm 2$ \\
\hline $\mathrm{V}_{\text {total }}\left(\mathrm{cm}^{3} / \mathrm{g}\right)$ & 0.816 \\
\hline Particle diameter $\left(\mathrm{d}_{\mathrm{p}}\right)$ & $180-250 \mu \mathrm{m}$ \\
\hline
\end{tabular}

\subsection{FTIR Analysis:}

FTIR spectra are a useful tool to identify functional groups in a molecule, as each specific chemical bond often has a unique energy adsorption band, and can obtain structural and bond information on a complex to study the strength and the fraction of hydrogen bonding and miscibility (Zhou et al., 2004). The spectrum Figure (1) shows a strong and broad adsorption peak appeared at at $3433 \mathrm{~cm}^{-1}$ indicated the presence of the $\mathrm{O}-\mathrm{H}$ group of phenol. The methylene group (aliphatic) is detected by $\mathrm{C}-\mathrm{H}$ stretching at a wave number of 2919 and $2852 \mathrm{~cm}^{-1}$. The aldehyde group of $-\mathrm{O}-\mathrm{CH}_{3}$ is found around $2853 \mathrm{~cm}^{-1}$. IR band around $1445 \mathrm{~cm}^{-1}$ indicate to stretching $\mathrm{C}=\mathrm{O}$ of 
carboxyl or carbonyl groups, a strong band at about $1079 \mathrm{~cm}^{-1}$ corresponding to $\mathrm{C}-\mathrm{O}$ stretching in acids, alcohols, phenols, ethers and esters and (Lua, and Yang, 2005) and (Mahmoudi et al., 2014).

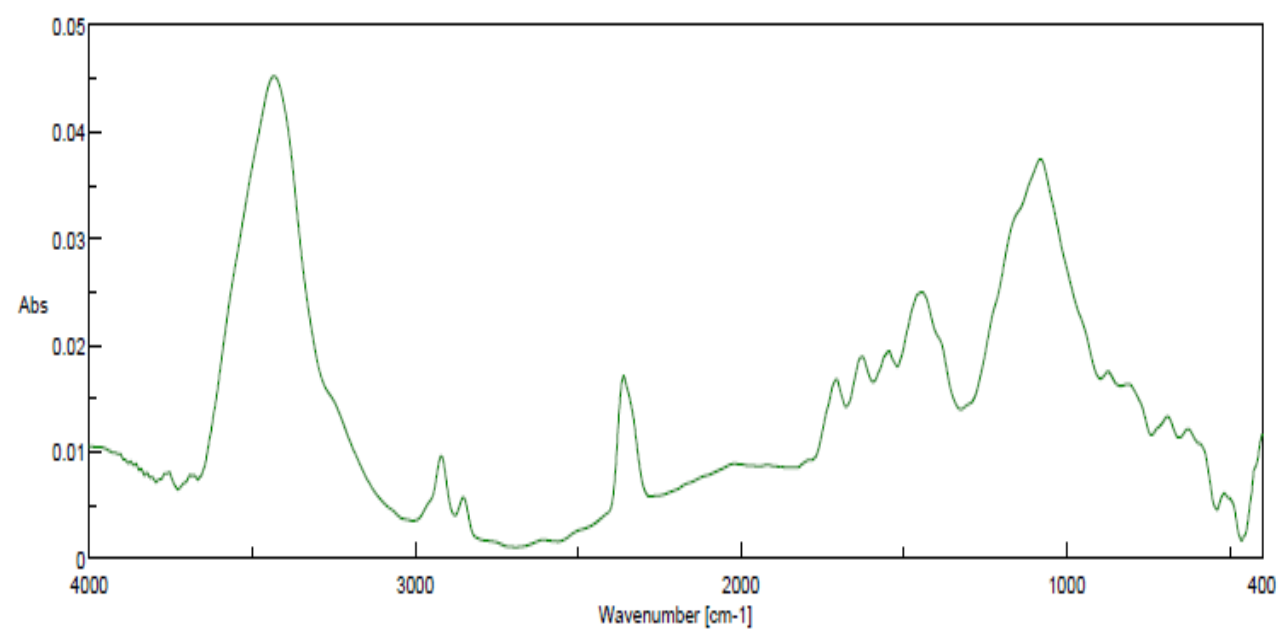

Figure (1): FTIR for Date pits activated carbon (DPAC)

\section{Effect of Contact Time:}

The adsorption capacity and required contact time are two of the most important parameters to understand in an adsorption process (Ho and McKay, 1998). It is noted from Figure (2) that the removal of PCP species is rapid in the initial stages of contact time and gradually decreases with lapse of time until saturation and attains equilibrium in 120 minutes for initial concentrations 500 and $1000\left(\mu \mathrm{g} . \mathrm{dm}^{-3}\right)$ of PCP solutions at temperature $25^{\circ} \mathrm{C}$, however, equilibrium experiments were run for 240 minutes to insure that the adsorption process achieved the state of equilibrium. 


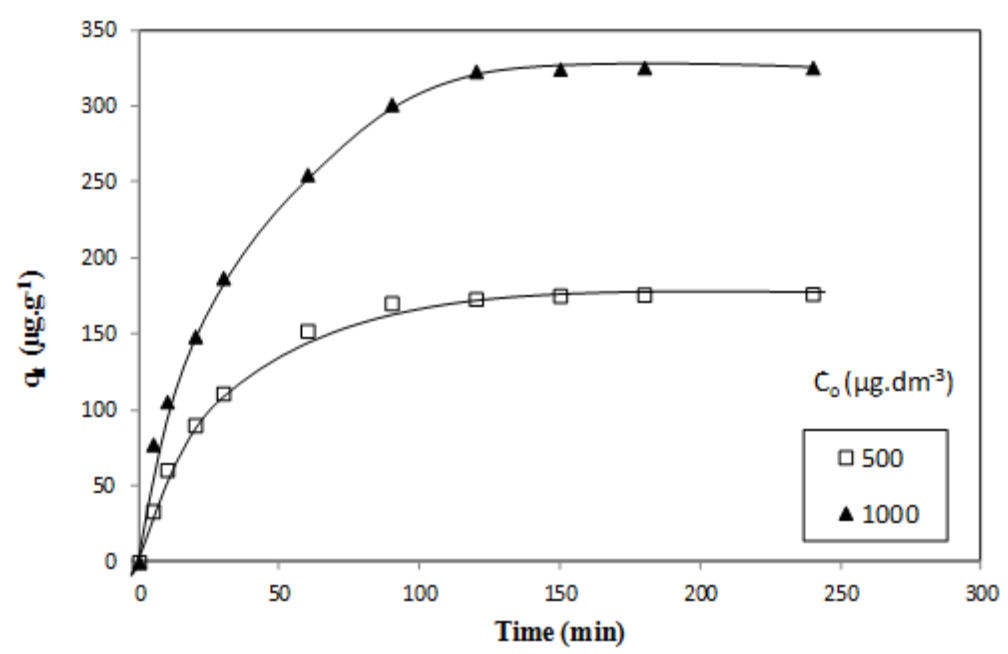

Figure (2): Equilibrium Time for the Adsorption of PCP onto DPAC at Different Initial Concentrations at $25 \pm^{\circ} \mathrm{C}$

\section{Effect of pH:}

The effect of $\mathrm{pH}$ on the adsorption of DPAC for $\mathrm{pH}$ ranging between 2 and 11 is illustrated in Figure (3). The uptake amounts of PCP adsorbed qe $(\mu \mathrm{g} / \mathrm{g})$, at acidic $\mathrm{pH}$ remained constant or decreased slightly with the $\mathrm{pH}$, however at $(\mathrm{pH}=9)$ a sharp decrease in adsorption capacity is observed. These results are in accordance with results obtained by Ali et al., (2008) for adsorption of para-chlorophenol onto (Date pits-clay) carbon composite from aqueous media; also with Abdel-Ghani et al.,(2015), for adsorption of pentachlorophenol onto activated carbon prepared from corn wastes from aqueous media. According to Abdel-Ghani et al., (2015), PCP exists entirely in the anionic form at neutral and basic $\mathrm{pH}$. Therefore, electrostatic repulsion between the negatively charged adsorbent surface and the anionic PCP will take place leading to lower adsorption. 
J. Environ. Sci.

Institute of Environmental Studies and Research - Ain Shams University

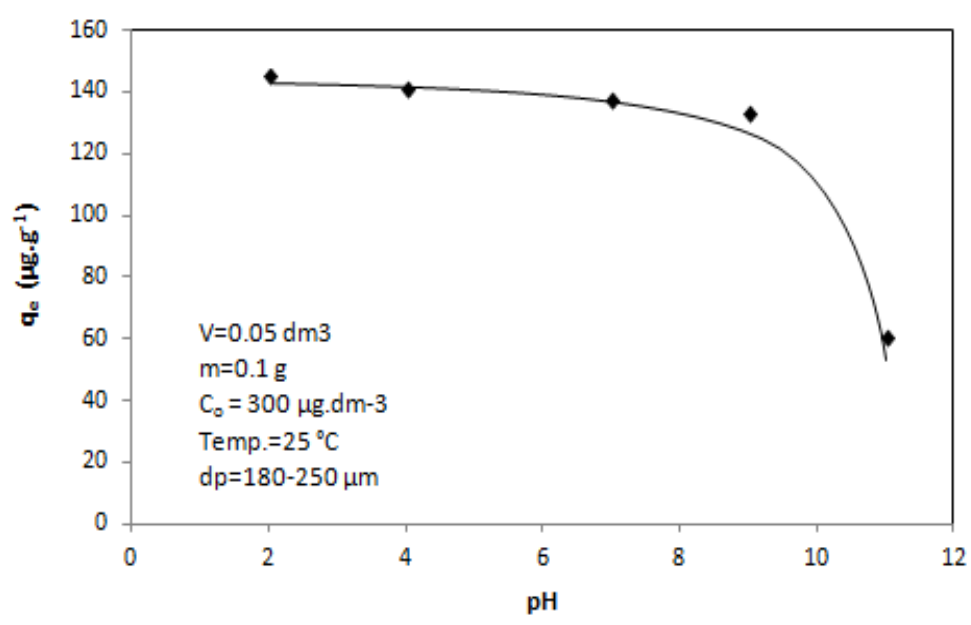

Figure (3): Effect of $\mathrm{pH}$ on the adsorption capacity of PCP onto date -pit activated carbon at Temp. $=25^{\circ} \mathrm{C}$.

\section{Equilibrium modeling:}

The adsorption data have been subjected to different four adsorption isotherms, namely Langmuir, Freundlich, Temkin and Redlich-Peterson models at different temperature $25,35,45$ and $55^{\circ} \mathrm{C}$. Figures $4.5,6$ and 7 show the linearization plots of the applied isotherm models at different temperatures. The results suggest the applicability of the Langmuir isotherm and demonstrate monolayer coverage of the adsorbate on the outer surface of the adsorbent. The isotherm models parameters obtained for adsorption of PCP on the DPAC at different temperatures are listed in Table 2. The adsorption process was favorable as Langmuir separation factor, $\mathrm{R}_{\mathrm{L}}$ was $0<\mathrm{R}_{\mathrm{L}}<1$ and supported by $n$ value of Freundlich which were more than one. A value for $n$ over one indicates a Langmuir-type isotherm because it becomes more and more difficult to adsorb additional adsorbate molecules at higher and higher adsorbate concentrations (Konstantinos et al., 2007) 


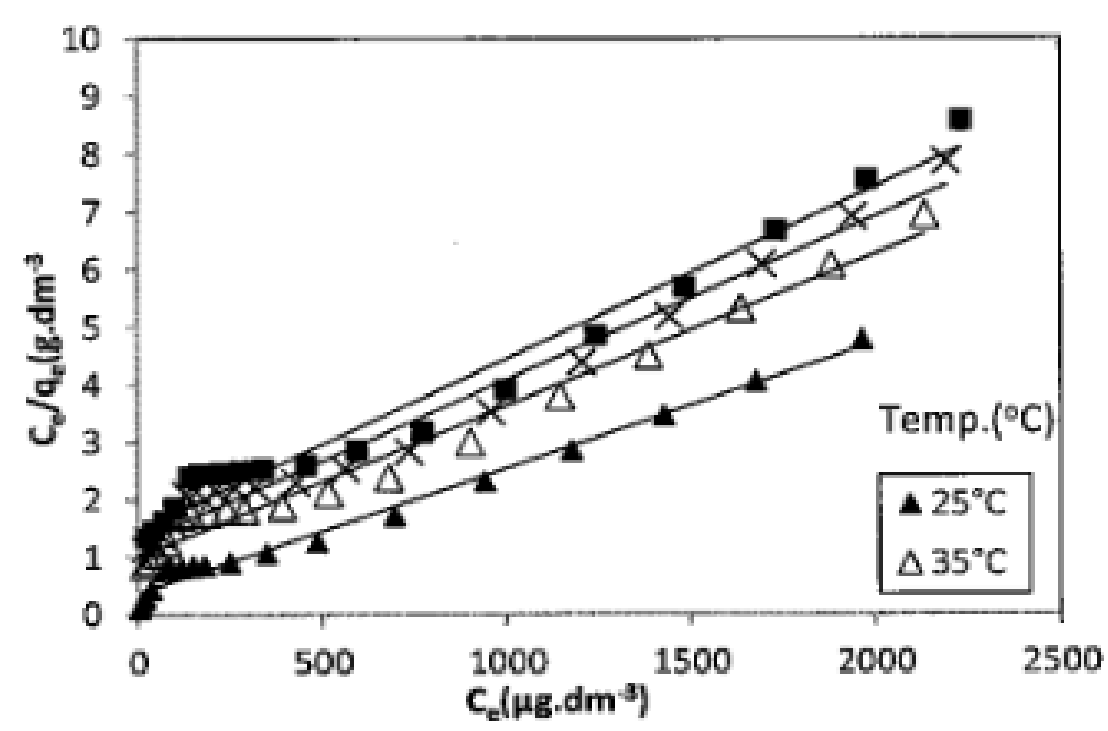

Figure (4): Langmuir plot for the adsorption of PCP onto DPAC at different temperatures.

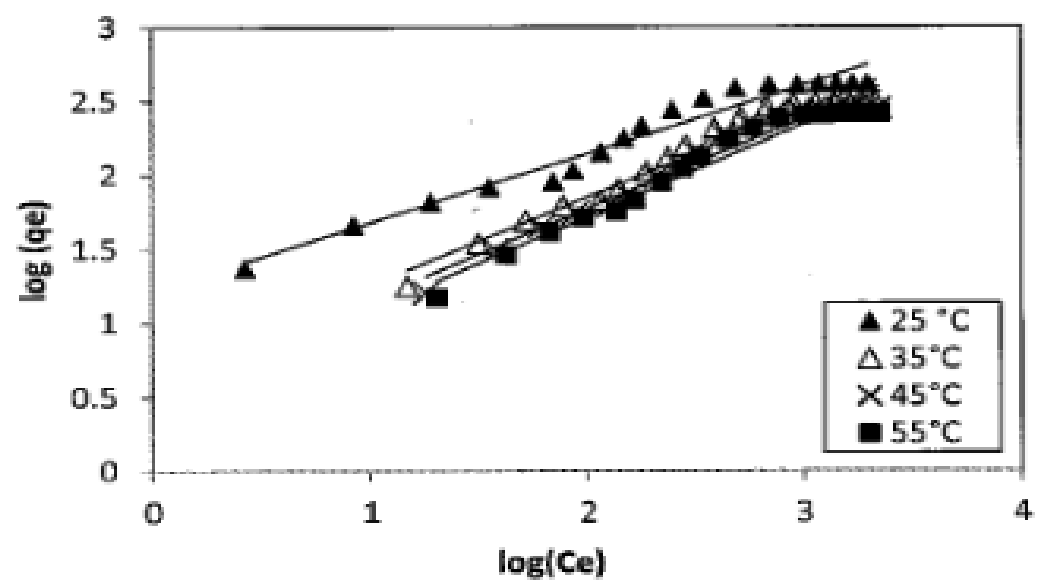

Figure (5): Frendulich plot for the adsorption of PCP onto DPAC at different temperatures. 


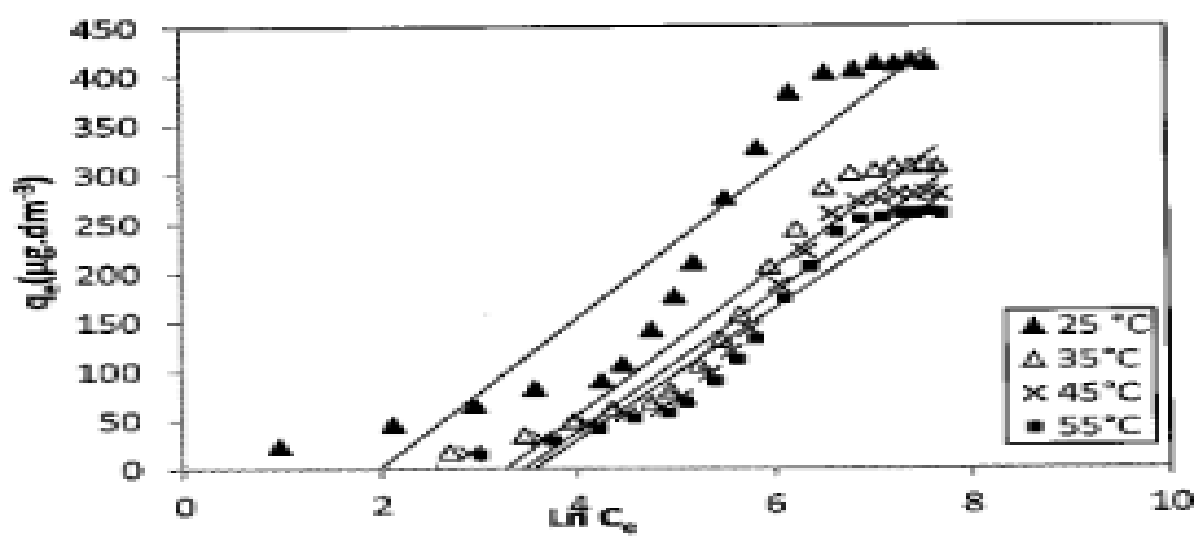

Figure (6): Tekmin plot for the adsorption of PCP onto date-pits activated carbon.

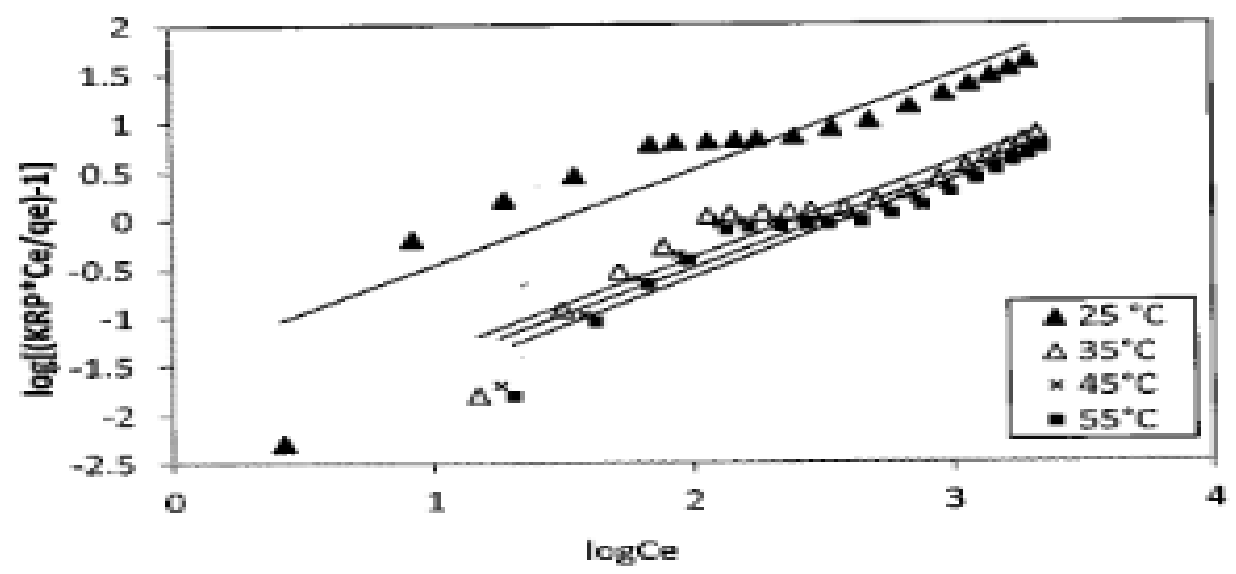

Figure (7): Redlich- Petroson plot for the adsorption of PCP onto date-pits activated carbon. 
Table 2: Estimated Langmuir, Freundlich and Temkin isotherm models parameters for adsorption of PCP onto DPAC at different temperatures.

\begin{tabular}{|c|c|cccc|}
\hline Isotherm Model & Parameters & \multicolumn{4}{|c|}{ Temp. $\left({ }^{\circ} \mathbf{C}\right)$} \\
\hline \multirow{4}{*}{ Langmuir } & & $25^{\circ} \mathrm{C}$ & $35^{\circ} \mathrm{C}$ & $45^{\circ} \mathrm{C}$ & $55^{\circ} \mathrm{C}$ \\
\cline { 2 - 6 } & $\mathrm{K}_{\mathrm{L}}$ & 2.7548 & 1.0025 & 0.7912 & 0.6788 \\
& $\mathrm{a}_{\mathrm{L}}$ & 0.0055 & 0.00260 & 0.00221 & 0.00203 \\
& $\mathrm{R}_{\mathrm{L}}$ & 0.1337 & 0.2174 & 0.2383 & 0.2491 \\
\hline \multirow{2}{*}{ Frendulich } & $\mathrm{K}_{\mathrm{f}}$ & 16.48 & 4.607 & 3.490 & 2.919 \\
& $\mathrm{n}$ & 2.163 & 1.690 & 1.631 & 1.598 \\
\hline \multirow{2}{*}{ Temkin } & $\mathrm{b}_{\mathrm{T}}$ & 32.685 & 34.544 & 34.544 & 41.161 \\
& $\mathrm{~A}_{\mathrm{T}}$ & 0.1379 & 0.0382 & 0.0319 & 0.0287 \\
\hline \multirow{3}{*}{ Redlich-Peterson } & $\mathrm{K}_{\mathrm{RP}}$ & 8.985 & 1.209 & 0.899 & 0.745 \\
& $\mathrm{a}_{\mathrm{RP}}$ & 0.03617 & 0.00466 & 0.00380 & 0.00264 \\
& $\beta$ & 0.9709 & 0.9691 & 0.9602 & 0.9912 \\
\hline
\end{tabular}

\section{Simulation and Correlation}

Figure 4 show the graphical comparison between the experimental and predicted data for PCP onto DPAC using the four applied equilibrium models equations ( Langmuir, the Freundlich, the Temkin, and the Redlich-Peterson isotherm) and the estimated values of their parameters. So it could be concluded that the Langmuir model be best to fit the experimental data according to graphical representations and error function values.

The applicability of the isotherm models to fit the adsorption data was compared by judging the correlation coefficients, $\mathrm{R}^{2}$ and average relative error values. The closer the $\mathrm{R}^{2}$ value to unity and the smaller ARE value, the better the fit. Based on the tabulated values of correlation coefficient $\left(R^{2}\right)$ and Average relative error (ARE), it can be concluded that the adsorption of PCP on DPAC was demonstrated well by Langmuir isotherm model 
compared to other models. The correlation coefficient, $\mathrm{R}^{2}$ for this model is 0.987 and ARE value is 21.424.

Table (3): Simulation and correlation values for the Adsorption of PCP onto DPAC using Different Models.

\begin{tabular}{|l|c|c|}
\hline \multicolumn{1}{|c|}{ Isotherm modelT $\mathbf{~ 2 5}^{\mathbf{}} \mathbf{C}$} & ARE & $\mathbf{R}^{\mathbf{2}}$ \\
\hline Langmuir & 21.424 & 0.9876 \\
\hline Freundlich & 84.194 & 0.9595 \\
\hline Temkin & 240.21 & 0.8860 \\
\hline Redlich-Peterson & 39.307 & 0.8080 \\
\hline
\end{tabular}

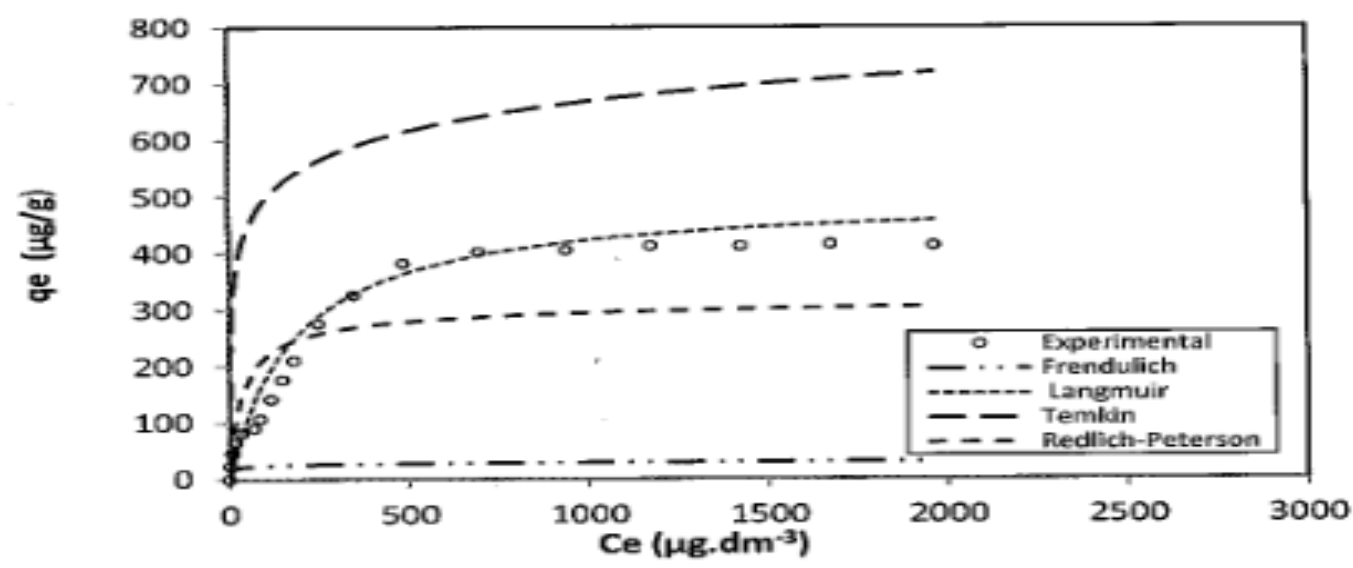

Figure (8): Adsorption isotherm of PCP onto date -pit activated carbon at $25 \pm 1^{\circ} \mathrm{C}$.

\section{Thermodynamics study:}

Results in Table (2) reveled that the value of $\mathrm{K}_{\mathrm{L}}$ decrease with increasing temperature suggesting that the adsorption of PCP on DPAC is exothermic in nature. The thermodynamic parameters that must be considered to determine the process are changes in standard enthalpy $\left(\Delta \mathrm{H}^{\circ}\right)$, standard entropy $\left(\Delta \mathrm{S}^{\mathrm{o}}\right)$ 
and standard Gibbs free energy $\left(\Delta \mathrm{G}^{\mathrm{o}}\right)$ due to transfer of unit mole of solute from solution onto the solid-liquid interface. The Gibbs free energy change of adsorption is defined as:

$$
\Delta \mathrm{G}^{\mathrm{o}}=-\mathrm{RT} \ln \mathrm{K}_{\mathrm{L}}
$$

Where $\left(\mathrm{K}_{\mathrm{L}}\right)$ is Langmuir equilibrium constant, $(\mathrm{R})$ is the universal gas constant (8.314 J.g-mol $\left.{ }^{-1} \cdot \mathrm{K}^{-1}\right)$ and $(\mathrm{T})$ is the absolute temperature $(\mathrm{K})$. The values of $\left(\Delta \mathrm{H}^{\circ}\right)$ and $\left(\Delta \mathrm{S}^{\circ}\right)$ was computed using Van't Hoff equation (Cheung et al., 2009) :

$$
\ln K_{L}=\frac{\Delta S^{o}}{R}-\frac{\Delta H^{o}}{R T}
$$

A plot of $\left(\ln \mathrm{K}_{\mathrm{L}}\right)$ versus (1/T) (Figure 5) should produce straight line with slope equals to $-\Delta \mathrm{H}^{\circ} / \mathrm{RT}$ and intercept equals to $\Delta \mathrm{S}^{\mathrm{o}} / \mathrm{R}$ The calculated values of $\left(\Delta \mathrm{H}^{\mathrm{o}}\right)$ and $\left(\Delta \mathrm{S}^{\mathrm{o}}\right)$ and $\left(\Delta \mathrm{G}^{\mathrm{o}}\right)$ are listed in Table (3).

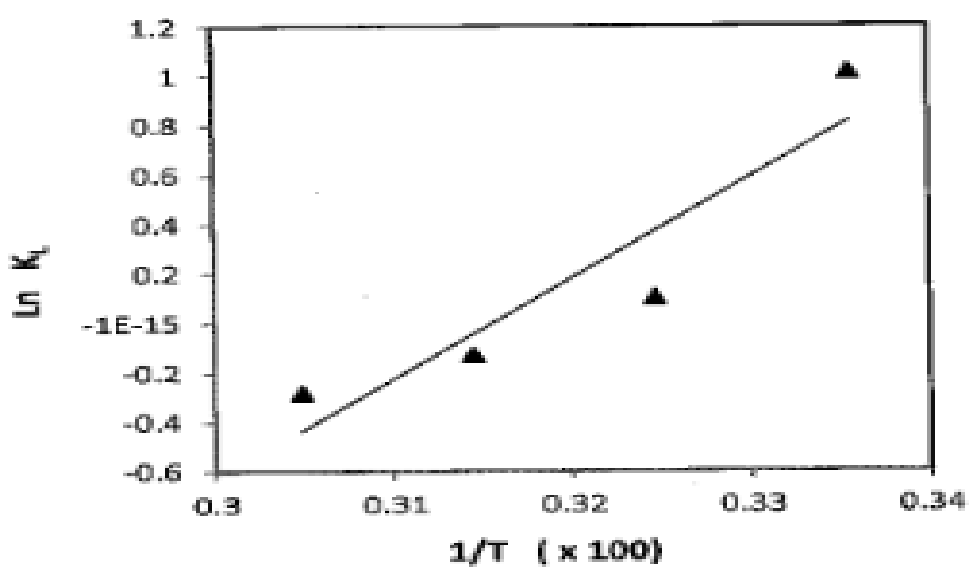

Figure (9): Plot of $\mathrm{K}_{\mathrm{L}}$ against 1/T for adsorption of PCP onto DPAC 
J. Environ. Sci.

Institute of Environmental Studies and Research - Ain Shams University

Table (3): Thermodynamic parameters of PCP adsorption onto DPAC

\begin{tabular}{|c|c|c|c|}
\hline Temp. $\left({ }^{\circ} \mathrm{C}\right)$ & $\begin{array}{c}G^{O} \\
\text { KJ.mol }^{-1}\end{array}$ & $\begin{array}{l}\Delta H^{o} k \\
J . m o l^{-l}\end{array}$ & $\begin{array}{c}\Delta \boldsymbol{S}^{O} \\
\mathbf{J}^{\prime} \mathrm{mol}^{-1} \cdot \mathrm{K}^{-1}\end{array}$ \\
\hline 25 & -2.510 & \multirow{4}{*}{$-36 . .500$} & \multirow{4}{*}{-115.947} \\
\hline 35 & -0.0064 & & \\
\hline 45 & 0.6192 & & \\
\hline 55 & 1.0565 & & \\
\hline
\end{tabular}

The standard enthalpy $\left(\Delta \mathrm{H}^{\circ}\right)$ and entropy $\left(\Delta \mathrm{S}^{\circ}\right)$ changes of adsorption determined from equation (9) were found to be $-36.500\left(\mathrm{~kJ} \cdot \mathrm{mol}^{-1}\right)$ and $115.947\left(\mathrm{~J} . \mathrm{mol}^{-1} \cdot \mathrm{K}^{-1}\right)$, respectively. The magnitude of $\left(\Delta \mathrm{H}^{\mathrm{o}}\right)$ for physical adsorption ranges from 4 to $40\left(\mathrm{~kJ} \cdot \mathrm{g}-\mathrm{mol}^{-1}\right)$, compared to that of chemical adsorption ranging from 40 to $800\left(\mathrm{~kJ} . \mathrm{g}-\mathrm{mol}^{-1}\right)$ (Crini and Badot, 2008). The negative value of $\left(\Delta \mathrm{H}^{\circ}\right)$ for PCP onto DPAC system indicates the exothermic nature of the process.

The negative value of $\Delta \mathrm{S}^{\circ}$, which indicate that there is a decrease in state of disorderness in the molecules during process, which in turn is due to the binding of molecules with adsorbent surface (Gupta et al., 2006).

\section{CONCLUSIONS}

This work investigated the equilibrium adsorption of pentachlorophenol (PCP) onto prepared date-pit activated carbon (DPAC) at different temperatures. Langmuir isotherm was found to have the best fit to the experimental data over the whole concentration range with the lower average relative error (ARE) and higher correlation coefficient $\left(\mathrm{R}^{2}\right)$ values, 21.424 and 0.9876 respectively. Thermodynamic parameters indicate that the adsorption of PCP on DPAC is exothermic process. The adsorption capacity 160 
of PCP remained constant or decreased slightly at $\mathrm{pH}(2-9)$, followed by a sharp decrease by further increasing in $\mathrm{pH}$.

\section{REFERENCES}

Abdel-Ghani N.T.; El-Chaghaby, G. A.; Zahran, E. M. (2015): "Pentachlorophenol (PCP) adsorption from aqueous solution by activated carbons prepared from corn wastes", International Journal of Environmental Science and Technology, Volume 12, $\mathrm{p}: 211-222$.

Abdulkarim, M. A.; Darwish, N. A.; Magdy Y. M. and Dwaidar, A. (2002): "Adsorption of phenolic compounds and methylene blue onto activated carbon prepared from date fruit pits", Engineering in Life Sciences Volume 2, Issue 6, 161-165.

Ali, M. M. S.;Abdel Rahman, N. and EL-Said, N. (2012): "Removal of some pollutants phenol derivatives by (DP-clay) carbon composite from aqueous media", Isotope \& RAD. Res., Volume 44 (1), p:253266.

Al-Attas, O. (2003): "The Production of Activated Carbon from Local PalmDate Pits for Pollution Removal Process". M.Sc. Thesis, Civil Eng., King Fahd University of Petroleum and Minerals, K.S.A.

Al-Jlil, S. A. (2012), "2,4-Dicchlorophenoxyzcetic acid" Int. J. Chem. Sci. Volume 10 (2), p: 677-690.

Al-Muhtaseb, S.A.; El-Naas, M. H.; Abdallah, S., (2008): "Removal of aluminum from aqueous solutions by adsorption on date-pit and BDH activated carbons", Journal of Hazardous Materials, Volume 158, p: $300-307$.

Banat, F.; Al-Asheh, S. and Al-Rousan, D., (2002): "A comparative study of copper and zinc ion adsorption on to activated and non-activated date-pits", Adsorpt. Sci. Technol., Volume 20 (4), p: 319-335. 
Banat, F.; Al-Asheh S., and Al-Makhadmeh L. (2003):"Kinetics and equilibrium study of cadmium ion sorption onto date pits: an agricultural waste", Adsorpt. Sci. Technol., Volume 21 (3), $\mathrm{p}: 245-260$.

Cheung, W.H.; Szeto, Y.S. and McKay, G. (2009): "Enhancing the adsorption capacities of acid dyes by chitosan nanoparticles", Bioresour. Technol., Volume 100, p: 1143-1148.

Crini, G.; Gimbert, F.; Robert, C.; Martel, B.; Adam, O.; Morin-Crini, N.; Giorgi, F.D. and Badot, P. (2008): "The removal of Basic Blue 3 from aqueous solutions by chitosan-based adsorbent: Batch studies". J. Hazard. Mater., Volume 153, p:96-106.

El-Geundi, M.S. (1991): "Colour removal from textile effluents by adsorption techniques". Water Res., Volume 25, p:271-273.

Esmael, A.I.; Matta, E.M.; Halim H.; Abdel Azziz, F.M. (2014): "Adsorption of Heavy Metals from Industrial Wastewater using Palm Date Pits as Low Cost Adsorbent", International Journal of Engineering and Advanced Technology (IJEAT), Volume 3, p:71-76.

Ghosh, M.K.; Ghosh, U.K.; and Kumar, S. (2011): "Minimization of Phenols and Phenolic Compounds in Pulp and Paper Industries: Biological Approaches" J. Chem. Chem. Eng., Volume 5, p:595-607.

Kapoor, A. and Yang, R.T. (1989)": "Correlation of equilibrium adsorption data of condensable vapors on porous adsorbents". Gas. Sep. Purif., Volume 3 (4), p:187-192.

Konstantinos, F., Garyfallia, D. and Nikolaos, R. (2007): "Headspace SolidPhase Microextraction for the Gas Chromatographic Analysis of Organophosphorus Insecticides in Vegetables" , J. AOAC Int., Volume 90, p: 1677-1681.

Lua, A.C., Yang, T.J. (2005): "Characteristics of activated carbon prepared from pistachio-nut shell by zinc chloride activation under nitrogen and vacuum conditions", Colloid. Interf. Sci., Volume 52, p:290305. 
Mahmoudi, K., Hamdi N., Srasra E., (2014): "Preparation and characterization of activated carbon from date pits by chemical activation with zinc chloride for methyl orange adsorption", J. Mater. Environ. Sci., Volume 5 (6), p:1758-1769.

Merzougui, Z; Addoun F. (2008): "Effect of oxidant treatment of date pit activated carbons application to the treatment of waters", Desalination, Volume 222, p:394-403.

Praus, P. (2003): "Drinking Water Disinfection and Formation of Byproducts" Technické univerzity Ostrava Řadahornickogeologická, Volume 2, p: 95-102.

Sumathi ,S. and Hung Y. (2004): "Treatment of pulp and paper mill wastes", in: L.K. Wang, Y.-T. Hung, H.H. Lo, C. Yapijakis The Hand Book of Industrial Hazardous Waste Treatment, 2nd Edn., Marcel Dekker Inc., USA, p: 469-513.

Temkin, M. I. (1941): "Adsorption equilibrium and the kinetics of processes on nonhomogeneous surfaces and in the interaction between adsorbed molecules", Zh. Fiz.Chim., Volume 15, p: 296-332.

Treybal, R, E, (1985): "Mass transfer operation", 3rd Edn.; New York, U.S., McGraw-Hill Book Company.

Weber,T. W. and Chakravort R. K., (1974): "Pore and Solid Diffusion Models for Fixed-Bed Adsorbers", Aiche J., Volume 20, p: 228232. 


\section{إذالا ماتلا خماسيه علورثينول هن المحاليل المائية

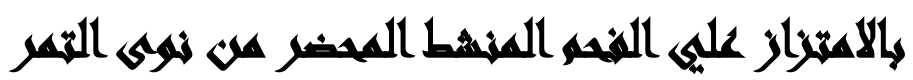

\section{[V]}

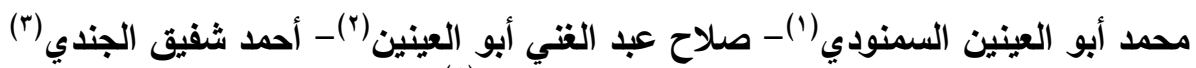

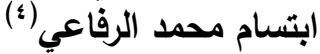

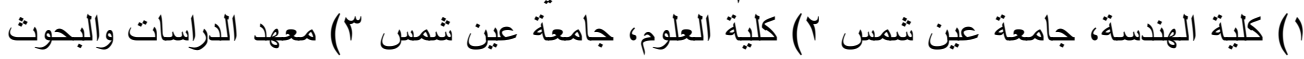

$$
\begin{aligned}
& \text { البيئية، جامعة عين شمس ع ) الريئة العامة للبترول }
\end{aligned}
$$

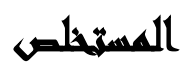

تعرف مركبات الهاليدات العضوية القابلة للامنزاز بأنها مواد سامة تنتج كنواتج ثانوية لتعقيم مياه

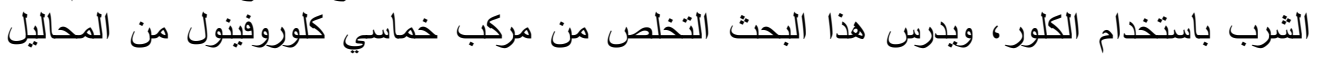

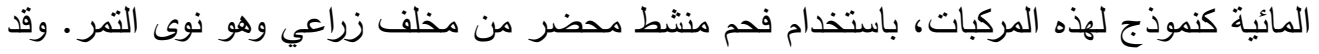

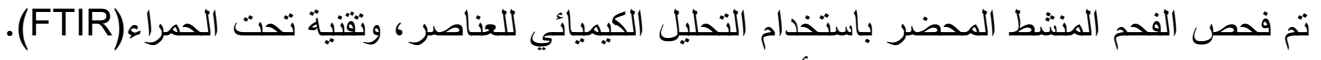

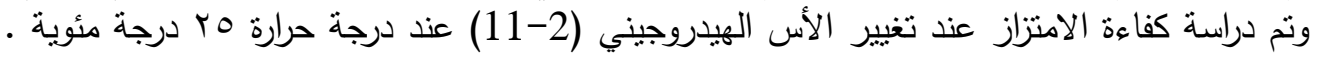

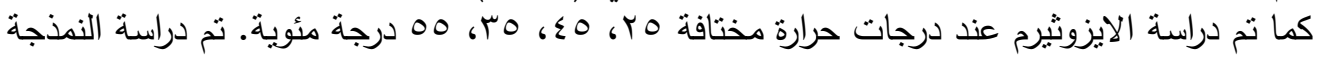

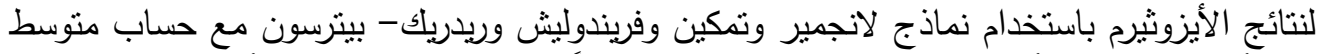

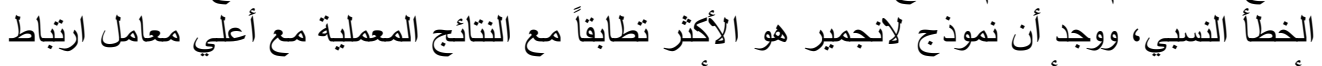

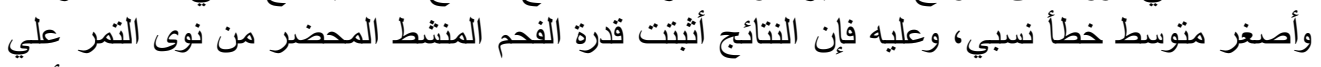

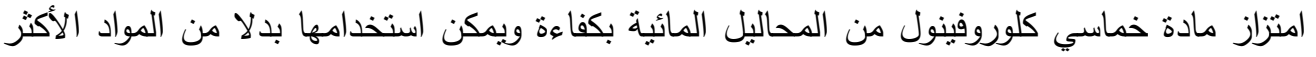

